\title{
Impact of simulation-based teamwork training on COVID-19 distress in healthcare professionals
}

\author{
Anna Beneria ${ }^{1,2}$, Mireia Arnedo², Sofia Contreras ${ }^{2,3}$, Marco Pérez-Carrasco ${ }^{2,3}$, Itziar Garcia-Ruiz ${ }^{2,4}$, \\ Mónica Rodríguez-Carballeira², Joaquim Raduà $5,6,7,8$ and Jordi Bañeras Rius ${ }^{2, *^{*}}$ (D)
}

\begin{abstract}
Context: Non-technical skills such as leadership, communication, or situation awareness should lead to effective teamwork in a crisis. This study aimed to analyse the role of these skills in the emotional response of health professionals to the COVID-19 pandemic.

Methods: Before the COVID-19 outbreak, 48 doctors and 48 nurses participated in a simulation-based teamwork training program based on teaching non-technical skills through simulation. In May 2020, this group of professionals from a COVID-19 referral hospital was invited to participate in a survey exploring stress, anxiety, and depression, using the PSS-14 (Perceived Stress Scale) and the HADS (Hospital Anxiety and Depression Scale) measures. A control group that did not receive the training was included. We conducted a logistic regression to assess whether having attended a simulation-based teamwork training program modified the probability of presenting psychological distress (PSS-14 > 18 or HADS> 12).

Results: A total of 141 healthcare professionals were included, 77 in the intervention group and 64 in the control group. Based on the PSS-14, 70.1\% of the intervention group and 75\% of the control group ( $p=0.342$ ) had symptoms of stress. Having contact with COVID-19 patients [OR 4.16(1.64-10.52)]; having minors in charge [OR 2.75 (1.15-6.53)]; working as a doctor [0.39(0.16-0.95)], and being a woman [OR 2.94(1.09-7.91)] were related with PSS14 symptoms. Based on the HADS, $54.6 \%$ of the intervention group and $42.2 \%$ of the control group ( $p=0.346$ ) had symptoms of anxiety or depression. Having contact with COVID-19 patients [OR 2.17(1.05-4.48)] and having minors in charge [OR 2.14(1.06-4.32)] were related to HADS symptoms. Healthcare professionals who attended COVID-19 patients showed higher levels of anxiety and depression [OR 2.56(1.03-6.36) $(p=0.043)]$.
\end{abstract}

Conclusion: Healthcare professionals trained in non-technical skills through simulation tended towards higher levels of anxiety and depression and fewer levels of stress, during the COVID-19 pandemic.

Keywords: COVID19 distress, Healthcare workers wellbeing, Simulation and teamwork

\footnotetext{
*Correspondence: jbaneras@vhebron.net

${ }^{2}$ Vall Hebron centre Simulació Clínica Avançada (VHiSCA), Direcció Docència, Vall d'Hebron Hospital Universitari, Vall d'Hebron Barcelona Hospital Campus, Barcelona, Spain

${ }^{9}$ Cardiology Vall d'Hebron Hospital Universitari, 08036 Barcelona, Spain

Full list of author information is available at the end of the article
}

(C) The Author(s). 2020 Open Access This article is licensed under a Creative Commons Attribution 4.0 International License, which permits use, sharing, adaptation, distribution and reproduction in any medium or format, as long as you give appropriate credit to the original author(s) and the source, provide a link to the Creative Commons licence, and indicate if changes were made. The images or other third party material in this article are included in the article's Creative Commons licence, unless indicated otherwise in a credit line to the material. If material is not included in the article's Creative Commons licence and your intended use is not permitted by statutory regulation or exceeds the permitted use, you will need to obtain permission directly from the copyright holder. To view a copy of this licence, visit http://creativecommons.org/licenses/by/4.0/ The Creative Commons Public Domain Dedication waiver (http://creativecommons.org/publicdomain/zero/1.0/) applies to the data made available in this article, unless otherwise stated in a credit line to the data. 


\section{Background}

On March 11, 2020, the World Health Organization declared the severe acute respiratory syndrome coronavirus 2 (SARS-CoV-2) outbreak a pandemic disease [1]. Emotionally traumatic experiences such as this pandemic can cause stress-related disorders [2, 3]. Indeed, we previously reported that $65 \%$ of a Spanish sample of 5000 individuals reported anxiety or depressive symptoms during the COVID-19 outbreak [4].

Healthcare professionals (HP) are a high-risk population group since they have faced a huge challenge and psychological stress, anxiety, and depression from pandemics [5, 6]. Indeed, given the critical situation that we are experiencing, HP who are directly involved in the diagnosis, treatment, and care of COVID-19 patients may develop symptoms related to psychological suffering that can trigger other mental health symptoms.

The unique nature of intense working relationships in crises requires not only technical skills but also nontechnical competencies related mainly to leadership, communication, and situation awareness [7]. To prepare people for these scenarios, simulation-based teamwork training (SBTT) becomes an essential resource, since it should help to develop the skill and competency of HP to cope with the stress associated with emergencies and disasters [8]. Contexts of education and professional practice have profound effects on the substance and quality of learning outcomes and on how professional competence is expressed clinically [9]. SBTT offers learning in a safe container with a high-fidelity psychological environment, without repercussion on the patient. In addition to training non-technical skills, the acute stress responses in SBTT do not differ when comparing with real situations [10]. Besides, it has been observed that in simulation scenarios, biological stress markers are detected [11] and that the performance of the team in stressful situations is a function of the non-technical skills of the leader [12]. This suggests that simulation can be a powerful ally to prepare HP for better coping in stressful situations, even showing a decrease in work stress levels in nurses from intensive care units, keeping the positive effects at 6 months of follow-up [13].

COVID-19 has become the biggest health crisis in decades and has become a stressful context for HP. There is a lack of knowledge about the impact of an SBTT intervention on stress, anxiety, and depression levels in this health emergency. This work aims to study the effect of an SBTT program on stress, anxiety, and depression levels during the onset of the COVID-19 crisis in HP.

\section{Methods}

\section{Study design}

This was a prospective observational cohort study to determine the effect of having received an SBTT on stress, anxiety, and depression levels. The study was carried out in a single tertiary hospital. With the declaration of COVID-19 as a pandemic, our hospital became a COVID-19 reference centre, admitting more than 2700 patients during the first two months.

\section{Participants}

All HP who had received an SBTT, 48 doctors and 48 nurses from different medical specialties, were invited to participate in a psychological survey and were designated as the intervention group (IG). The control group (CG) was built by inviting to participate $134 \mathrm{HP}$ who had no contact with simulation training.

\section{Intervention courses}

The Vall Hebron Advanced Clinical Simulation centre (VHiSCA), has conducted three editions (from November 2019 to March 2020), of an SBTT instructor course, 32 HP having participated in each one. The course had a mixed design with a total of $25 \mathrm{~h}$ and was divided into online $(13 \mathrm{~h})$ and on-site practical part (12 h). As VHIS CA has just started the formation with HP we had implemented it with medical practitioners and not with delegates yet. The main objectives were to provide basic knowledge on healthcare simulation, to provide skills to be a simulation instructor, to acquire non-technical skills management, and to master briefing and debriefing. From our SBTT instructor course database we know that only $9 \%$ of the participants had taken a simulation instructor course prior to the intervention.

\section{Stress, anxiety and depression instrument}

A Survey format was designed including two scales. The Hospital Anxiety and Depression Scale (HADS) [14, 15] was applied to assess the level of anxiety and depression. The HADS has been widely used in the clinical setting and has been validated for the Spanish population [15] and demonstrated an optimal internal consistency and test-retest reliability in the Spanish non-clinical population [16]. It is composed of 14 items and evaluates 7 items for each dimension. In this study, scores $>12$ were considered positive for anxiety and depression domain [15]. A 12-15 cut-off could be appropriate for a nonclinical population [16] with a sensibility and specificity of over 70\% [17]. The Perceived Stress Scale-14 (PSS-14) $[18,19]$ was used to evaluate stress. This scale has 14 items that evaluate stress perceived in the last month. Both scales have already been used in studies with HP $[20,21]$ and responded with a four-point Likert scale. Based on previous literature [16, 18, 19] we analysed groups with cut-off scores, HADS $>12$ and PSS14 > 18 . 


\section{Data collection and ethical approval}

After approval by the ethical committee of Vall d'Hebron University Hospital (PR (AG)261/2020), and within the third month of the pandemic, HP were invited to participate in the study through corporate email. Informed consent was asked, and data was obtained anonymously. The survey was first sent to the IG. To collect data for the CG, participants were asked to invite a co-worker with no experience in simulation to participate.

\section{Data analysis}

For the descriptive analysis, categorical data are shown as frequency and percentage, and differences between groups were analysed using the chi-square test. For continuous variables, normal distribution was tested by the Kolmogorov-Smirnov test; data following a normal distribution is shown as mean and standard deviation and differences were analysed using the Student's t-test.

Effect sizes for continuous variables were analysed using the between-group mean difference (95\% confidence interval). Logistic regression was used to assess whether having attended the simulation-based teamwork training program modified the probability of having stress, anxiety, or depressive symptoms. The effects of sex, age, working with COVID-19 positive patients, having minors in charge, being married and professional category were considered. Sub-analyses were performed based on exposure to COVID-19. The statistical significance level was set at $p<0.05$. Statistical software packages STATA 15.1 was used for all data analyses.

\section{Results}

A total of $141 \mathrm{HP}$ completed the online survey, 77 $(80.2 \%)$ in the IG, and 64 (47.8\%) in the CG. The demographic characteristics of both groups are shown in Table 1.

In the IG, the HADS score mean was 14.23 (SD 7.41) and in the CG was 12.08 (SD 6.66), mean difference2.15 (95\% CI $-4.52-0.22$ ). Based on the HADS, $54.6 \%$ of the IG and $42.2 \%$ of CG ( $p=0.346)$ had symptoms of anxiety or depression. Significant differences were observed only in HP in contact with COVID-19 patients $(p=0.037)$ and having minors in charge $(p=0.033)$ (Table 2).

PSS-14 score mean was 23.92 (SD 8.65) in the IG and 24.33 (SD 9.00) in the CG, mean difference 0.41 (95\% CI $-2.54-3.36)$. Based on the PSS-14, $70.1 \%$ of the IG and $75 \%$ of the CG $(p=0.342)$ had symptoms of stress. Significant differences were observed in HF in contact with COVID-19 patients $(p=0.003)$, having minors in charge $(p=0.022)$, working as a doctor $(p=0.038)$, and being a woman $(p=0.033)$ (Table 2).

Based on previous results, we performed a sub-analysis only with HP who had attended COVID-19 patients $(n=88), 51(58 \%)$ in the IG, and $37(42 \%)$ in the CG Healthcare professionals that had attended COVID-19 patients showed higher levels of anxiety and depression [OR $2.56(1.03-6.36)(p=0.043)]$. (Table 3).

\section{Discussion}

This study provides results about the impact of an SBTT program on stress, anxiety, and depression in HP during a crisis. We found that in the IG when they were

Table 1 Baseline demographic characteristics. Data were expressed as frequency (\%) and mean (SD)

\begin{tabular}{|c|c|c|c|}
\hline & Instructors $(n=77)$ & Controls $(n=64)$ & $p$ \\
\hline \multicolumn{4}{|l|}{ Sex } \\
\hline Female & $54(70.1 \%)$ & $54(84.4 \%)$ & 0.047 \\
\hline Male & $23(29.9 \%)$ & $10(15.6 \%)$ & \\
\hline Age (years) & $41.9(8.1)$ & $38.5(9.1)$ & 0.020 \\
\hline Couple / married & $39(50.6 \%)$ & $26(40.6 \%)$ & 0.234 \\
\hline Minors & $45(58.4 \%)$ & $26(40.6 \%)$ & 0.035 \\
\hline Professional category & & & 0.633 \\
\hline Doctors & $38(49.4 \%)$ & $29(45.3 \%)$ & \\
\hline Nurses & 39 (50.6\%) & $35(54.7 \%)$ & \\
\hline Workplace: COVID area & $51(66.2 \%)$ & $37(57.8 \%)$ & 0.304 \\
\hline Contact with COVID-19 patients & & & 0.282 \\
\hline Daily & $42(54.6 \%)$ & $34(53.1 \%)$ & \\
\hline Weekly (> 1 day per week) & $28(36.4 \%)$ & $19(29.7 \%)$ & \\
\hline Occasionally (< 5 days per month) & $4(5.2 \%)$ & $3(4.7 \%)$ & \\
\hline Rarely & 3 (3.9\%) & 8 (12.5\%) & \\
\hline
\end{tabular}


Table 2 Logistic regression of variables related with HADS > 12 and PSS14 > 18 between intervention and control group

\begin{tabular}{llll}
\hline & & Odds Ratio (95\% Cl) & $\boldsymbol{p}$ \\
\hline HADS > 12 & COVID-19 & $2.17(1.05-4.48)$ & 0.037 \\
& Minors in charge & $2.14(1.06-4.32)$ & 0.033 \\
PSS14 > 18 & COVID-19 & $4.16(1.64-10.52)$ & 0.003 \\
& Minors in charge & $2.75(1.15-6.53)$ & 0.022 \\
& Working as doctor & $0.39(0.16-0.95)$ & 0.038 \\
& Women & $2.94(1.09-7.91)$ & 0.033 \\
\hline
\end{tabular}

exposed to COVID-19 care patients, they suffered more anxiety and depression levels (HADS) than the HP who did not receive the education SBTT program. To our knowledge, this is the first study focusing on mental health symptomatology on SBTT participants.

HP taking care of patients with COVID-19 are at risk of developing psychological distress and other mental health symptoms [22]. Numerous psychiatric or psychological departments, psychological counselling centres, and university psychology units have launched specialized programs to attend HP in hospitals, through telematics systems, telephone lines, and apps, to provide psychological treatment in crisis. In this context, we found that HP who have received an SBTT program presented more anxiety and depression when dealing with COVID-19 patients. Firstly, higher perception and awareness levels are observed after SBTT [23], and usually, these professionals are more involved and committed in education tasks in hospitals, entailing otherwise more responsibility tasks. Another study found similar results showing a relationship between awareness attitude, anxiety experience, and perceived mental health care needs in the community during the COVID19 pandemic [24]. Secondly, collective efficacy was independently associated with flow in simulation practice, but no

Table 3 Logistic regression of variables related to HADS> 12 and PSS14 > 18 between intervention and control group depending on the hospital area where they worked (COVID or No COVID). SBTT simulation-based teamwork training

\begin{tabular}{clll}
\hline & & Odds Ratio $(\mathbf{9 5} \% \mathrm{Cl})$ & $\boldsymbol{p}$ \\
\hline COVID-19 & & & \\
HADS> 12 & Performance SBTT & $2.56(1.03-6.36)$ & 0.043 \\
& Working as doctor & $0.35(0.132-0.94)$ & 0.038 \\
PSS14> 18 & Working as doctor & $0.19(0.06-0.60)$ & 0.005 \\
No COVID-19 & & & \\
HADS>12 & Minors in charge & $4.25(1.17-15.45)$ & 0.028 \\
PSS14> 18 & Minors in charge & $4.14(1.21-14.12)$ & 0.023 \\
& Sex Female & $5.74(1.21-36.26)$ & 0.63 \\
\hline
\end{tabular}

significant results were found for stress and self-esteem [25].

As in our study conducted in the general population [4], we observed that individuals with minors in charge and women had higher anxiety and depressive symptoms. Besides, we also found that HP who worked with COVID-19 patients had more symptoms of stress, anxiety, and depression, and women had more symptoms of stress probably related to the working environment, huge workload, long-term fatigue, infection threat, and frustration with the death of patients whom they care. There is evidence that healthcare simulation improves healthcare performance and degree of retention of what is learned when compared to all traditional teaching methods [26]. Our study results show that the emergency together with the knowledge of these abilities by part of the entire working group may be determining factors for the psychological state of the skills previously trained by using SBTT.

Despite that, it is necessary to keep working on stress levels in HP during the simulation and in real settings. Simulation educators need to create scenarios that purposely change stress to enhance learning as it was found that psychological stress and anxiety is greater during simulation compared with hospital settings [27]. The intervention used is a faculty training programme rather than a simulation based education programme for delegates. Subsequent research should focus on studying the degree of distress that students present in crisis situations based on the profile of the educator. Besides, health professions education programs must build student competencies in the affective domain of learning [28].

For this reason, it is crucial to be able to train professionals, promoting skills through SBTT that increases job security and reduces levels of distress generated in crises, both in technical aspects (performing cardiopulmonary resuscitation, placement of line or tube, tracheostomy, etc.) as in non-technical skills (communication, situational awareness, etc.) because stress triggers diseases and increases health resources.

\section{Strengths and limitations}

Study strengths are that it is the first study focus on stress, anxiety, and depression in simulation instructors after a pandemic, and it combined different new areas never studied before, such as professional's health and simulation training after COVID-19.

We acknowledge that our survey has several limitations. Firstly, there is likely to have been a degree of selection bias in the CG. Secondly, the number surveyed varied greatly between the two groups. Thirdly, we cannot rule out the presence of residual confounders. 


\section{Conclusion}

HP trained in non-technical skills as simulation instructor had a tendency towards higher levels of anxiety and depression and fewer levels of stress, during the COVID-19 pandemic, being significant in the case of anxiety and depression in HP who directly attended COVID-19 patients. Studies with structured interventions, randomized controlled trials, with larger homogeneous samples, can provide more information. Therefore, more studies with these characteristics should be done before being able to conclude the effectiveness of simulation-based techniques.

\section{Acknowledgements}

The authors are grateful to all the members of Teaching Department of Vall d'Hebron Hospital Universitari and all the members of Comissió Técnica Suport a la Simulació of Vall Hebron Advanced Clínical Simulation centre (VHiSCA), specially CR, TA, SC, EA, MJ, LM, AB, DL, MdN, MJ.

\section{Authors' contributions}

All the authors have contributed to the intervention. AB, SC, MPC, IGR and JB have contributed to the design. $M A, A B, S C$ and $J B$ have contributed to acquisition. MPC, IGR, AB, SC, MRC, JR and JB participate in the analysis and interpretation. All the authors have revised the work. They all agree to be accountable for all aspects of the work in ensuring that questions related to the accuracy or integrity of any part of the work are appropriately investigated and resolved. All the authors have read and approved the manuscript.

\section{Funding}

Authors have no affiliations with or involvement in any organization or entity with any financial interest or non-financial interest in the subject matter or materials discussed in this manuscript.

\section{Availability of data and materials}

The datasets used and/or analyzed the current study are available from the corresponding author on reasonable request.

\section{Ethics approval and consent to participate}

This study was approved by the ethical committee of Vall d'Hebron University Hospital (PR (AG)261/2020). Informed consent was asked, and data was obtained anonymously.

\section{Consent for publication}

Not applicable.

\section{Competing interests}

No additional financial or other affiliation relevant to the subject of this article is reported.

\section{Author details \\ 'Departament Psiquiatria, Vall d'Hebron Hospital Universitari, Barcelona, Spain. ${ }^{2}$ Vall Hebron centre Simulació Clínica Avançada (VHiSCA), Direcció Docència, Vall d'Hebron Hospital Universitari, Vall d'Hebron Barcelona Hospital Campus, Barcelona, Spain. ${ }^{3}$ Servei de Medicina Intensiva, Vall d'Hebron Hospital Universitari, Barcelona, Spain. ${ }^{4}$ Unitat Medicina Materna i Fetal, Department d'Obstetrícia, Vall d'Hebron Hospital Universitari, Universitat Autònoma de Barcelona, Barcelona, Spain. ${ }^{5}$ Institut d'Investigacions Biomèdiques August Pi i Sunyer (IDIBAPS), Barcelona, Spain. ${ }^{6}$ CIBERSAM, ISC-III, Madrid, Spain. ${ }^{7}$ King's College London, London, UK. ${ }^{8}$ Karolinska Institutet, Stockholm, Sweden. ${ }^{9}$ Cardiology Vall d'Hebron Hospital Universitari, 08036 Barcelona, Spain.}

Received: 12 August 2020 Accepted: 6 December 2020 Published online: 21 December 2020

\section{References}

1. Cucinotta D, Vanelli M. WHO declares COVID-19 a pandemic. Acta Biomed. 2020;91(1):157-60. https://doi.org/10.23750/abm.v91i1.9397.
2. Cosić K, Popović S, Šarlija M, Kesedžić I. Impact of Human Disasters and COVID-19 Pandemic on Mental Health: Potential of Digital Psychiatry. Psychiatr Danub. 2020;32(1):25-31. https://doi.org/10.24869/psyd.2020.25.

3. World Health Organization; 1992. World Health Organization. Psychosocial consequences of disasters: Prevention and management.

4. Fullana MA, Hidalgo-Mazzei D, Vieta E, Radua J. Coping behaviors associated with decreased anxiety and depressive symptoms during the COVID-19 pandemic and lockdown. J Affect Disord. Published online 2020. https://doi. org/10.1016/j.jad.2020.06.027.

5. Lee SM, Kang WS, Cho AR, Kim T, Park JK. Psychological impact of the 2015 MERS outbreak on hospital workers and quarantined hemodialysis patients. Compr Psychiatry. 2018:87:123-7.

6. Zhang WR, Wang $K$, Yin L, Zhao WF, Xue Q, Peng M, Min BQ, Tian Q, Leng HX, Du JL, Chang H, Yang Y, Li W, Shangguan FF, Yan TY, Dong HQ, Han Y, Wang YP, Cosci F, Wang HX. Mental health and psychosocial problems of medical health workers during the COVID-19 epidemic in China. Psychother Psychosom. 2020;100053(45). https://doi.org/10.1159/000507639.

7. $\mathrm{Hu} X, \mathrm{Chen} H, \mathrm{Yu}$ M. Exploring the non-technical competencies for onscene public health responders in chemical, biological, radiological, and nuclear emergencies: a qualitative study. Public Health. 2020;183:23-9. https://doi.org/10.1016/j.puhe.2020.04.015.

8. Shrestha R, Kanchan T, Krishan K. Simulation Training and Skill Assessment in Disaster Medicine. In: StatPearls [Internet]. Treasure Island (FL): StatPearls Publishing; 2020. Available from: https://www.ncbi.nlm.nih.gov/books/ NBK551719/. [Updated 2019 Nov 28].

9. McGaghie WC, Issenberg SB, Petrusa ER, Scalese RJ. A critical review of simulation-based medical education research: 2003-2009. Med Educ. 2010; 44(1):50-63. https://doi.org/10.1111/j.1365-2923.2009.03547.x.

10. Daglius Dias R, Scalabrini NA. Stress levels during emergency care: a comparison between reality and simulated scenarios. J Crit Care. 2016;33:813. https://doi.org/10.1016/j.jcrc.2016.02.010.

11. Valentin B, Grottke $\mathrm{O}$, Skorning $\mathrm{M}$, et al. Cortisol and alpha-amylase as stress response indicators during pre-hospital emergency medicine training with repetitive high-fidelity simulation and scenarios with standardized patients. Scand J Trauma Resusc Emerg Med. 2015;23(1):1-8. https://doi.org/10.1186/ s13049-015-0110-6.

12. Krage $R$, Zwaan $L$. Tjon Soei Len $L$, et al. relationship between non-technical skills and technical performance during cardiopulmonary resuscitation: does stress have an influence? Emerg Med J. 2017;34(11):728-33. https://doi.org/ 10.1136/emermed-2016-205754.

13. El Khamali R, Mouaci A, Valera S, et al. Effects of a multimodal program including simulation on job strain among nurses working in intensive care units a randomized clinical trial. JAMA - J Am Med Assoc. 2018;320(19): 1988-97. https://doi.org/10.1001/jama.2018.14284.

14. Zigmond A, Snalth R. The hospital anxiety and depression scale. Acta psychiatr. Scand. [revista en internet] 2014 [acceso 28 de noviembre de 2019]; 64(5): 361-370. Acta Psychiatr Scand. 1983;67(6):361-70. https://doi. org/10.1093/occmed/kqu024

15. Terol-Cantero M, Cabrera-Perona V, Martín-Aragón M. Hospital anxiety and depression scale (HADS) review in Spanish samples. An Psicol. 2015;31(2): 494-503. https://doi.org/10.6018/analesps.31.2.172701.

16. Terol MC, López-Roig S, Rodríguez-Marín J, Martín-Aragón M, Pastor MA, y Reig MT. Propiedades psicométricas de la Escala Hospitalaria de Ansiedad y Estrés (HAD) en población española. Ansiedad y Estrés. 2007;13(2-3):163-76.

17. Torres-lagunas MA, Vega-morales EG, Vinalay-carrillo I. Universitaria Validación psicométrica de escalas PSS-14, AFA-R , HDRS, CES-D , EV. en puérperas mexicanas con y sin preeclamsia. 2015;12(3):122-33.

18. Cohen S, Kamarck T, Mermelstein R. A global measure of perceived stress. J Health Soc Behav. 1983;24(4):385-96. https://doi.org/10.2307/2136404.

19. Trujillo HM, González-Cabrera JM. Psychometric properties of the Spanish version of the perceived stress scale (PSS). Psicol Conductual. 2007;15(3): 457-77.

20. Franco JC. Reducción de los niveles de estrés y ansiedad en médicos de Atención Primaria mediante la aplicación de un programa de entrenamiento en conciencia plena (mindfulness). Aten Primaria. 2010; 42(11):564-70. https://doi.org/10.1016/j.aprim.2009.10.020.

21. Paiva CE, Martins BP, Paiva BSR. Doctor, are you healthy? A cross-sectional investigation of oncologist burnout, depression, and anxiety and an investigation of their associated factors 11 medical and health sciences 1117 public health and health services 17 psychology and cognitive Scie. BMC Cancer. 2018;18(1):1-11. https://doi.org/10.1186/s12885-018-4964-7. 
22. Neto MLR, Almeida HG, D'arc Esmeraldo J, Nobre CB, Pinheiro WR, de Oliveira CRT, da Costa Sousa I, Lima OMML, Lima NNR, Moreira MM, Lima CKT, Júnior JG, da Silva CCL. When health professionals look death in the eye: the mental health of professionals who deal daily with the 2019 coronavirus outbreak. Psychiatry Res. 2020;288(April):2-4 https://doi.org/10. 1016/j.psychres.2020.112972.

23. Chang AL, Dym AA, Venegas-Borsellino C, Bangar M, Kazzi M, Lisenenkov D, Qadir N, Keene A, Eisen LA. Comparison between simulation-based training and lecture-based education in teaching situation awareness: a randomized controlled study. Ann Am Thoracic Soc. 2017;14(4):529-35 https://doi.org/ 10.1513/AnnalsATS.201612-9500C.

24. Roy D, Tripathy S, Kumar S, Sharma N. Study of knowledge, attitude, anxiety \& perceived mental healthcare need in T Indian population during COVID19 pandemic. Asian J Psychiatr. 2020;51:1-7 https://doi.org/10.1016/j.ajp. 2020.102083.

25. Kim MY, Park S. Associations of stress, self-esteem, and collective efficacy with flow in simulation among nursing students: a descriptive crosssectional study. Nurse Educ Today. 2018;71:193-7 https://doi.org/10.1016/j. nedt.2018.09.03.

26. Okuda Y, Bryson EO, DeMaria S Jr, et al. The utility of simulation in medical education: what is the evidence? Mt Sinai J Med. 2009;76:330-43.

27. Judd BK, Alison JA, Waters D, Gordon CJ. Comparison of psychophysiological stress in physiotherapy students undertaking simulation and hospital-based clinical education. Simul Healthc. 2016;11(4): 271-7 https://doi.org/10.1097/SIH.0000000000000155.

28. Donlan P. Developing affective domain learning in health professions education. J Allied Health. 2018;47(4):289-95.

\section{Publisher's Note}

Springer Nature remains neutral with regard to jurisdictional claims in published maps and institutional affiliations.

Ready to submit your research? Choose BMC and benefit from:

- fast, convenient online submission

- thorough peer review by experienced researchers in your field

- rapid publication on acceptance

- support for research data, including large and complex data types

- gold Open Access which fosters wider collaboration and increased citations

- maximum visibility for your research: over $100 \mathrm{M}$ website views per year

At $\mathrm{BMC}$, research is always in progress.

Learn more biomedcentral.com/submissions 